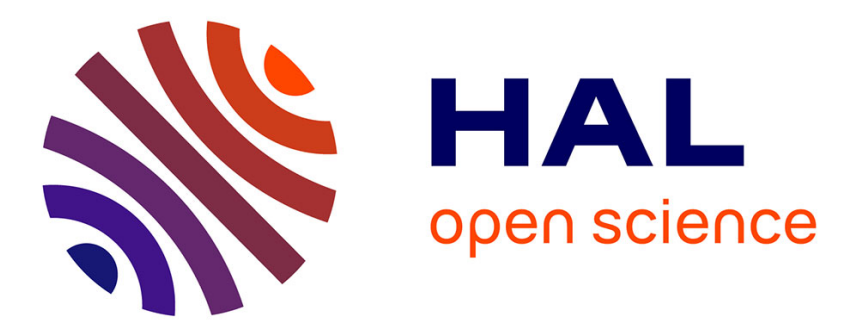

\title{
Formation of thin tungsten oxide layers: characterization and exposure to deuterium
}

Y Addab, Céline Martin, C Pardanaud, J Khayadjian, K Achkasov, D Kogut, G Cartry, G Giacometti, M Cabié, J Gardarein, et al.

\section{- To cite this version:}

Y Addab, Céline Martin, C Pardanaud, J Khayadjian, K Achkasov, et al.. Formation of thin tungsten oxide layers: characterization and exposure to deuterium. Physica Scripta, 2016, T167, pp.014036. 10.1088/0031-8949/T167/1/014036 . hal-03593478

\section{HAL Id: hal-03593478 \\ https://hal.science/hal-03593478}

Submitted on 2 Mar 2022

HAL is a multi-disciplinary open access archive for the deposit and dissemination of scientific research documents, whether they are published or not. The documents may come from teaching and research institutions in France or abroad, or from public or private research centers.
L'archive ouverte pluridisciplinaire $\mathbf{H A L}$, est destinée au dépôt et à la diffusion de documents scientifiques de niveau recherche, publiés ou non, émanant des établissements d'enseignement et de recherche français ou étrangers, des laboratoires publics ou privés.

\section{(ㅇ)(1) $\$$}

Distributed under a Creative Commons Attribution - NonCommercial - NoDerivatives| 4.0 


\title{
Formation of thin tungsten oxide layers: characterisation and exposure to deuterium.
}

\author{
Y. Addab ${ }^{a}$, C. Martin a,, C. Pardanaud ${ }^{a}$, J. Khayadjian ${ }^{a}$, K. Achkasov $^{\mathrm{a}}$, D. Kogut ${ }^{\mathrm{a}}$, \\ G. Cartrya , G. Giacomettia , M. Cabiéb, J.L Gardarein ${ }^{\mathrm{c}}$, and P. Roubina. \\ ${ }^{a}$ Aix-Marseille Université, CNRS, PIIM UMR 7345, 13397 Marseille \\ ${ }^{b}$ Aix-Marseille Université, CP2M, 13397 Marseille \\ 'Aix-Marseille Université, CNRS, IUSTI UMR 7343, 5 rue Enrico Fermi, 13453 Marseille
}

Thin tungsten oxide layers with thicknesses up to $250 \mathrm{~nm}$ have been formed on $\mathrm{W}$ surfaces by thermal oxidation following a parabolic growth rate. The reflectance of the layers in the IR range $2.5-16 \mu \mathrm{m}$ has been measured showing a decrease with the layer thickness especially at low wavelength. Raman microscopy and X-ray diffraction show a nanocrystalline $\mathrm{WO}_{3}$ monoclinic structure. Low energy deuterium plasma exposure $\left(11 \mathrm{eV} / \mathrm{D}^{+}\right)$has been performed inducing a phase transition, a change in the sample colour and the formation of tungsten bronze $\left(\mathrm{D}_{\mathrm{x}} \mathrm{WO}_{3}\right)$. Implantation modifies the whole layer suggesting a deep diffusion of deuterium inside the oxide. After exposure a deuterium release due to the oxidation of $\mathrm{D}_{\mathrm{x}} \mathrm{WO}_{3}$ under ambient conditions has been evidenced showing a reversible deuterium retention.

* Corresponding author : Celine MARTIN, email : celine.martin@univ-amu.fr

\section{Introduction}

Because of its favourable physical properties such as a low erosion yield, a high melting temperature, a high thermal conductivity and a low hydrogen isotope retention, tungsten is the material used for plasma facing components (PFCs) receiving highest fluxes in operating tokamaks (ASDEX-upgrade, JET-ILW) and will compose the ITER divertor. However, tungsten has a strong chemical affinity with oxygen and native oxide is naturally present on tungsten surfaces. On PFCs, oxide layers can be formed due to the presence of $\mathrm{O}_{2}$ as a contamination, PFCs high temperature, and in case of accidental scenarii such as lost of coolant accident or emergency shutdown. Oxidation will induce a modification of tungsten wall properties especially regarding the binding energy [1], the erosion yield [1,2], the reflectance and the deuterium retention $[3,4,5]$ which will depend on the structure, the stoechiometry and the thickness of the oxide layers formed.

$\mathrm{W}$ oxidation depends strongly on temperature and on the oxygen partial pressure. Gorbunova and Arslambekov showed that even at room temperature tungsten begins to oxidize [6], and the oxidation rate increases by increasing temperature. Under $673 \mathrm{~K}$ the growth law changes from a logarithmic to a 
parabolic law $[7,8,9]$. In the range $773-973 \mathrm{~K}$ the oxide layer cracks increasing the oxidation rate and from $1073 \mathrm{~K}$ oxide growth follows a linear law [10,11].

Thermodynamic and structural studies show that W-O system contains several stable oxides in defined temperature intervals [12]. The most currently studied are the monoclinic $\left(\mathrm{m}-\mathrm{WO}_{3}\right)$ and the orthorhombic (o- $\left.\mathrm{WO}_{3}\right)$ phases, stable in the range 290- $593 \mathrm{~K}$ and 593-993 K respectively, and the hexagonal phase $\left(\mathrm{h}-\mathrm{WO}_{3}\right)$ which is metastable $[10,13,14]$.

In this work, we produce thin $\mathrm{WO}_{3}$ layers which mimic the possible oxidation of W-PFCs in order to study the effects on their properties and their behaviour under low energy deuterium bombardment. Temperature was set at $673 \mathrm{~K}$ in order to be relevant for PFCs, and oxygen pressure was set at 590 Torr in order not to be limited by a low oxidation rate. The oxide thicknesses were measured by SEM on cross-sections prepared using a focused ion beam, their structure was obtained using X-ray diffraction (XRD), and the Raman spectra gave information on the local structure at the nanometric and micrometric scales. After deuterium plasma exposure, the same techniques allowed us to analyse their behaviour regarding deuterium irradiation. Previous investigations have shown that deuterium retention in $\mathrm{WO}_{3}$ is higher than in $\mathrm{W}$ due to a less dense structure, with channels or cracks involving a deeper diffusion of deuterium [4,5]. Deuterium can induce the reduction of $\mathrm{WO}_{3}$ and the formation of tungsten bronzes $\left(\mathrm{D}_{\mathrm{x}} \mathrm{WO}_{3}\right)[15,16]$ with chemically bonded or intercalated deuterium.

We study in this paper the deuterium bombardment of a $\mathrm{WO}_{3}$ layer about $130 \mathrm{~nm}$ thick formed on a polycrystalline $\mathrm{W}$ substrate. The experimental part is section 2 and characterisations of the oxide layers are detailed in section 3. Deuterium plasma exposure and the effects on the oxide layer are described in section 4 .

\section{Experimental part}

Polycrystalline rolled tungsten samples produced by Goodfellow, with a purity of $99.95 \mathrm{wt} \%$ were cut from a sheet $(0.3 \mathrm{~mm}$ thickness) and used as substrates for growing oxides. All the samples were polished to a mirror-like surface, electro-polished and cleaned in ultrasonic baths with acetone and ethanol. The samples roughness measured by AFM was about ten to twenty nanometres. SEM showed that the grain size was about $1 \mu \mathrm{m}$ and the grain elongation was parallel to the surface. The samples were outgassed under high vacuum $\left(\sim 10^{-7}\right.$ Torr $)$ at $673 \mathrm{~K}$ for 4 hours. They were thermally oxidized at the same temperature under 5 or 590 Torr of oxygen with times ranging from $30 \mathrm{~min}$ to $7 \mathrm{~h}$.

Characterisation of the layers formed was performed using complementary techniques. The oxide film thicknesses were measured on a cross-section using a FEI Helios 600 NanoLab dual beam which combines a focused ion beam (FIB) and a scanning electron microscope. X-ray diffraction (XRD) patterns were obtained by a Philips X'Pert diffractometer using a $\mathrm{CuK} \alpha$ source $(0.154 \mathrm{~nm})$ operating at $40 \mathrm{kV}, 40 \mathrm{~mA}$ and at $2 \theta=7-60^{\circ}$. Raman spectra were recorded using a Horiba-Jobin-Yvon HR 
LabRAM apparatus in the backscattering geometry $\left(\lambda_{\mathrm{L}}=514.5 \mathrm{~nm}\right.$, laser spot size $\left.\sim 1 \mu \mathrm{m}^{2}\right)$. The laser power was kept at about $1 \mathrm{~mW} / \mu \mathrm{m}^{2}$. The Raman mapping mode was used to average $\sim 50$ spectra collected over a $750 \mu \mathrm{m}^{2}$ area in order to increase the signal to noise ratio and thus averaging possible inhomogeneities of the sample. Spectra were measured in the range $100-1250 \mathrm{~cm}^{-1}$. Diffuse reflectance was measured on both virgin and oxidized samples in the wavelength range 2.5 - $16 \mu \mathrm{m}$ using a Nicolet NEXUS hemispheric reflectometer.

The oxidized samples were exposed to a capacitively coupled radio frequency $\mathrm{D}_{2}$ plasma $\left(1.5 \times 10^{-2}\right.$ Torr, $400 \mathrm{~W}$ ) in the setup described in [17]. Mass spectrometry measurements showed that the dominant ion population was $\mathrm{D}_{3}{ }^{+}: 82 \%$ of the total amount. It is assumed that dissociation takes place at surface impact and initial $\mathrm{D}_{3}{ }^{+}$ion energy is shared between the three fragments. The plasma potential measured by a Langmuir probe and verified by the mass spectrometer was about $33 \mathrm{~V}$ giving an incident energy of $11 \mathrm{eV} / \mathrm{D}^{+}$for ions impinging on the grounded sample. The deuterium ion fluence was fixed at $410^{17}$ $\mathrm{D}^{+} / \mathrm{cm}^{2}$ and exposure time was 15 minutes at room temperature. The samples were not significantly heated by the plasma itself.

\section{Characterisations}

We present here structural and optical properties of three samples oxidized $0.5 \mathrm{~h}, 1 \mathrm{~h}$ and $3 \mathrm{~h}\left(\mathrm{P}\left(\mathrm{O}_{2}\right)=590\right.$ Torr, $\mathrm{T}=673 \mathrm{~K}$ ). Oxide layers are firmly adherent and brightly coloured as shown in Figure 1 . Their colour which is due to interference phenomena, can give a rough estimation of the film thickness knowing the refractive index (which is about $2.20[18,19]$ ). The tungsten oxides was observed by SEM and showed as expected smooth surfaces with no cracks because of the low oxidation temperature. Xray diffraction shows a monoclinic $\left(\mathrm{m}-\mathrm{WO}_{3}\right)$ or orthorhombic $\left(\mathrm{o}-\mathrm{WO}_{3}\right)$ nanocrystalline structure. The lattice parameters of $\mathrm{m}-\mathrm{WO}_{3}$ and $\mathrm{o}-\mathrm{WO}_{3}$ phases are very close: $\mathrm{a}_{\mathrm{m}}=7.3271 \AA$, $\mathrm{b}_{\mathrm{m}}=7.5644 \AA, \mathrm{c}_{\mathrm{m}}=7.7274$ $\AA, \alpha_{\mathrm{m}}=90,000^{\circ}, \beta_{\mathrm{m}}=90,488^{\circ}, \gamma_{\mathrm{m}}=90,000^{\circ}$ (JCPDS 01-089-4476), $\mathrm{a}_{\mathrm{o}}=7.3410 \AA \mathrm{A}, \mathrm{b}_{\mathrm{o}}=7.5700 \AA$, $\mathrm{c}_{\mathrm{o}}=7.7540$ $\AA, \alpha_{0}=\beta_{0}=\gamma_{0}=90,000^{\circ}$ (JCPDS 01-071-0131) making them difficult to differentiate. They can be described as a layered framework in the ab plane, consisting of corner or edge-sharing $\mathrm{WO}_{6}$ octahedra, linked by oxygen [20]. These layers are stacked along the c-axis leading to the formation of channels between the octahedra in that direction. Figure 1 shows the thickness of the formed oxide layers measured by FIB cross-section: the $\mathrm{WO}_{3}$ layers formed are $100 \mathrm{~nm}, 134 \mathrm{~nm}$ and $255 \mathrm{~nm}$ for oxidation times of $0.5 \mathrm{~h}, 1 \mathrm{~h}$ and $3 \mathrm{~h}$, respectively. The error on thickness measurements is around $20 \%$, it corresponds to the standard deviation of the measurements done on several SEM images and to the uncertainty of defining the $\mathrm{WO}_{3} / \mathrm{W}$ interface. The thickness estimation given by the colour of the samples is in good agreement with the SEM cross-section measurement. 


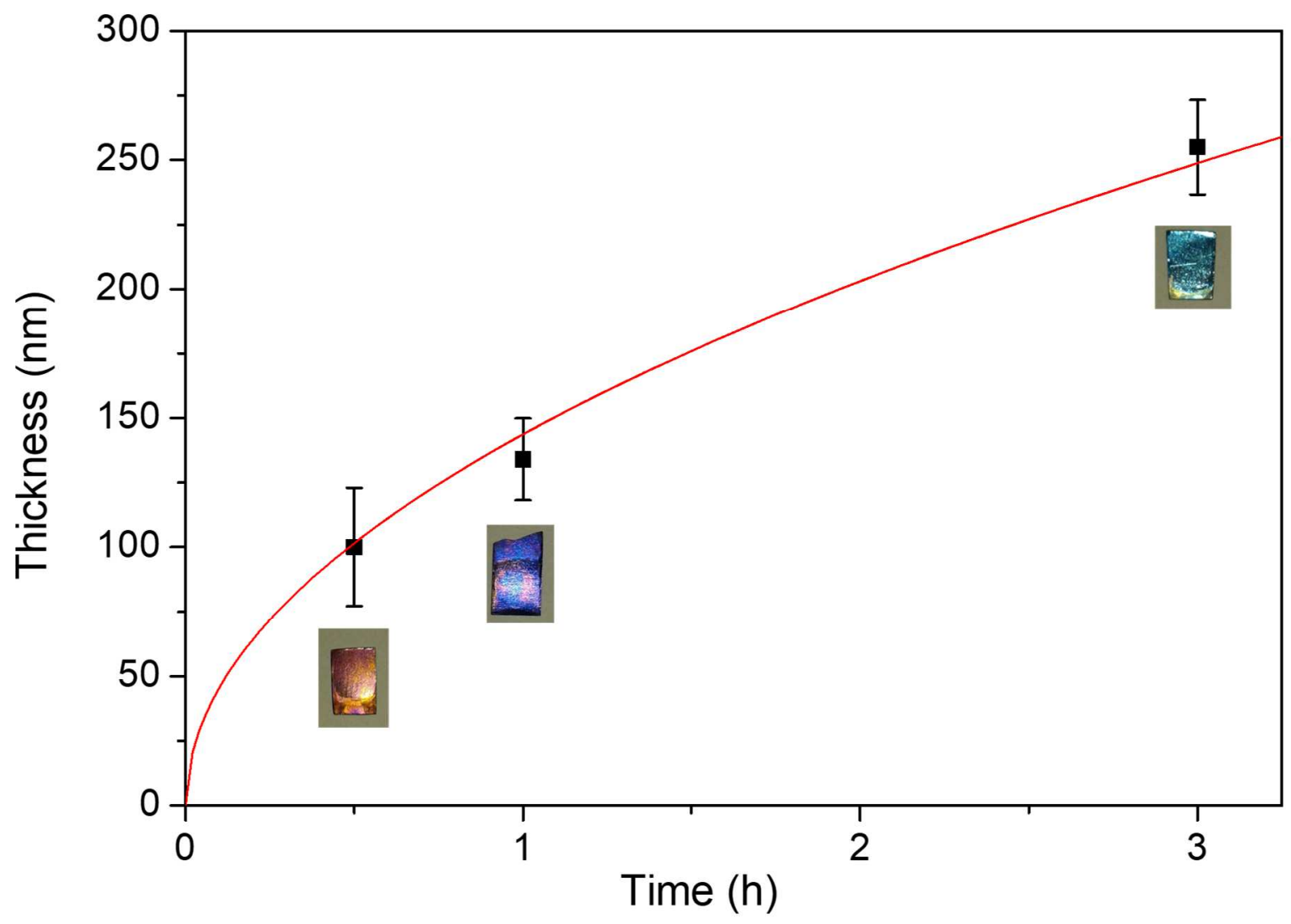

Fig. 1. Thicknesses of the $\mathrm{WO}_{3}$ layers formed at $673 \mathrm{~K}$ under $\mathrm{P}\left(\mathrm{O}_{2}\right)=590$ Torr versus oxidation time.

The red line corresponds to a parabolic law. Pictures show the film coloration depending on layer thickness.

As expected, the oxide thickness increases with oxidation time. We can observe a colour inhomogeneity due to thickness variation: the $\mathrm{W}$ sample surface state, both texture and roughness can induce a growth rate variation [5]. At $673 \mathrm{~K}$, oxidation is controlled by diffusion processes [9] and as mentioned previously, it follows a parabolic law. The Wagner model describes the oxide growth giving the evolution of the thickness layer (x) with time: $x^{2}=K t$ where $\mathrm{K}$ is the oxidation rate [21]. This constant depends on the Nernst potential $\mathrm{V}$ and can be expressed as $K=k^{\prime} V$ where $k^{\prime}$ is a parameter depending on the conductivity and molar volume of the oxide, and at a lesser extent on the $\mathrm{W}$ surface state. The Nernst potential $\mathrm{V}$ is a function of $\mathrm{T}$ and $\ln \mathrm{P}\left(\mathrm{O}_{2}\right)$ which are the experimental controlled parameters. In Figure 1, data are fitted by this law with $\mathrm{K}=2,0610^{4} \mathrm{~nm}^{2} / \mathrm{s}$. We checked that the ratio between the oxidation rate constants obtained for $\mathrm{P}\left(\mathrm{O}_{2}\right)=590$ Torr and 5 Torr (not shown here) is close to $\ln \mathrm{P}\left(\mathrm{O}_{2}\right)$ ratio, which shows a good agreement with the Wagner model. It is obvious that oxide growth modifies W surface optical properties and in particular diffuse IR reflectance was measured and analysed. Figure 2 shows the diffuse reflectance spectra of the oxide layers $\left(\mathrm{P}\left(\mathrm{O}_{2}\right)=590\right.$ Torr, $\left.\mathrm{T}=673 \mathrm{~K}\right)$ and of the virgin tungsten surface. It appears that oxide layers of 100-250 nm thick decrease the tungsten reflectance of 
about $10 \%$. The thicker the oxide layer, the more attenuated is the reflectance at low wavelengths. In ITER, thermal IR wall diagnostics will be done using a $3.5 \mu \mathrm{m}$ wavelength and figure 2 shows that the presence of a thin oxide layer will be a concern for the signal interpretation. The WEST thermal IR diagnostics will use a $1.6 \mu \mathrm{m}$ wavelength and would be more affected by an oxidation of tungsten surfaces. Further investigations are needed to help in the implementation of the diagnostics.

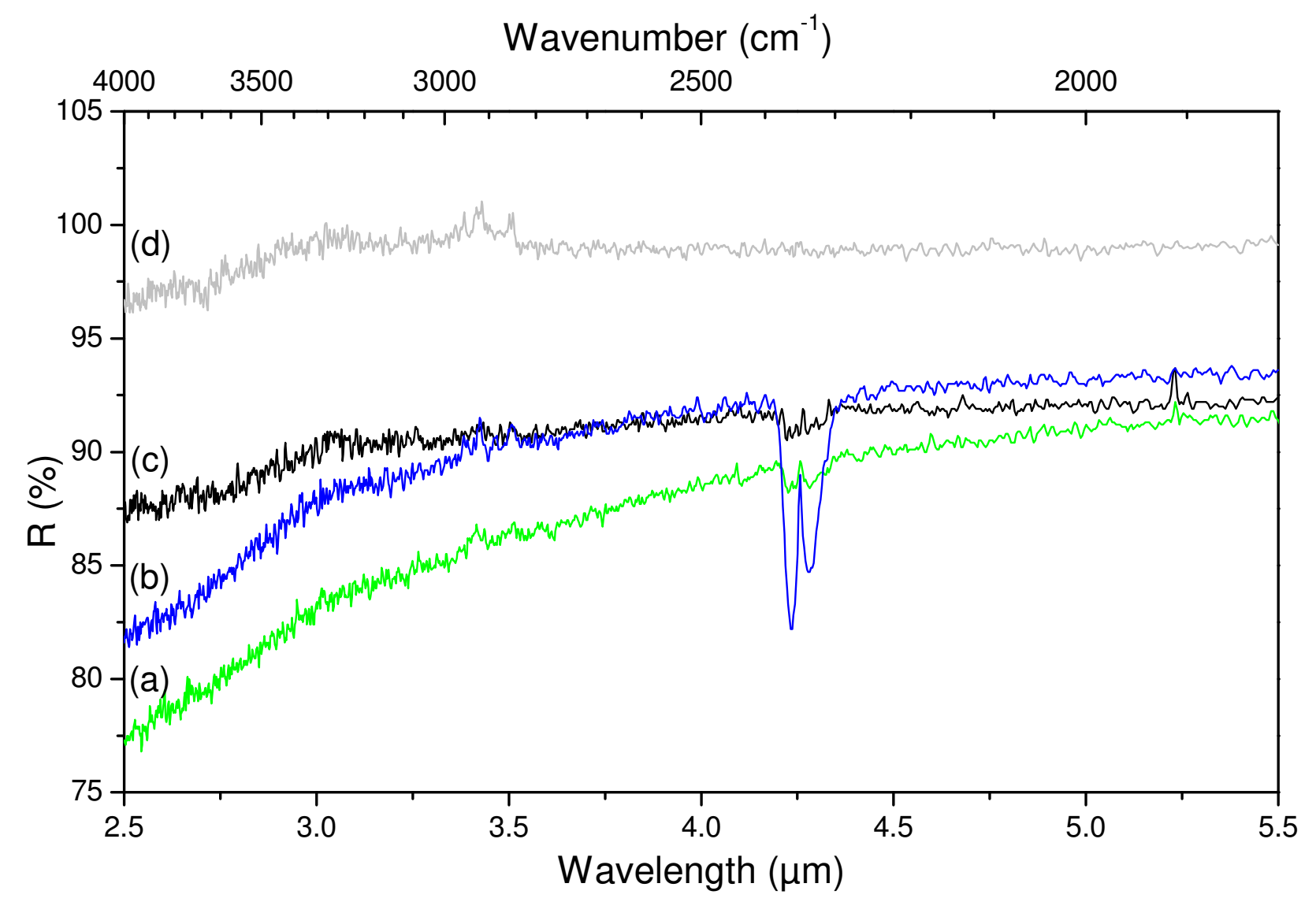

Fig. 2. Diffuse reflectance spectra of (a) $255 \mathrm{~nm}$, (b) $134 \mathrm{~nm}$, (c) $100 \mathrm{~nm}$ thick $\mathrm{WO}_{3}$ layers and of (d) virgin tungsten. The double band at $2350 \mathrm{~cm}^{-1}$ corresponds to the absorption of $\mathrm{CO}_{2}$ gas in the reflectometer. 


\section{Deuterium exposure}

We present here deuterium exposure of the tungsten sample oxidized $1 \mathrm{~h}$ at $673 \mathrm{~K}$ under 590 Torr $\mathrm{O}_{2}$ (see Fig. 1). The structure of the as-oxidized layers has been analysed using Raman microscopy and is in good agreement with $\mathrm{XRD}$, showing a $\mathrm{WO}_{3}$ nanocrystalline structure. Raman spectra of $\mathrm{WO}_{3}$ present three main vibration modes: stretching $\left(1000-500 \mathrm{~cm}^{-1}\right)$, bending $\left(500-100 \mathrm{~cm}^{-1}\right)$ and lattice modes (below $100 \mathrm{~cm}^{-1}$ ), only lattice modes make $\mathrm{m}-\mathrm{WO}_{3}$ and $\mathrm{o}-\mathrm{WO}_{3}$ differentiable [22].

Figure 3 presents normalized Raman spectra of the $134 \mathrm{~nm}$ thick $\mathrm{WO}_{3}$ layer in the stretching mode domain and a sample picture showing colour evolution, (3a) before and (3b) after deuterium plasma exposure. The first remarkable effect is that the colour of the sample has changed after deuterium exposure from purple/blue to orange/yellow. A few days later, its colour had become purple again. This suggests the existence of a reversible electrochromic effect in the oxide layer. The electrochromic effect involves the insertion of electrons and/or cations (such as protons) and leads to the formation of colouring centres $\left(\mathrm{W}^{5+}\right)$ [23]. The inserted cations could either reside into the structural channels created by the $\mathrm{WO}_{6}$ octahedra arrangement or react with the bridging oxygen [24,25] by breaking the network's $\mathrm{W}-\mathrm{O}-\mathrm{W}$ chains and creating new $\mathrm{W}=\mathrm{O}$ bonds [24]. The fact that tungsten bronzes $\left(\mathrm{H}_{\mathrm{x}} \mathrm{WO}_{3}\right)$ are easily oxidized to $\mathrm{WO}_{3}$ at room temperature by air [5] can explain the observed reversibility which has also been probed by Raman microscopy.

We display in Figure 3 the Raman spectrum of the oxide layer before and after bombardment. We have chosen to fit with 6 bands which have been previously attributed in the literature. Our methodology is to use the same fitting model and make qualitative comparisons before and after bombardment. Before exposure, we can observe in Figure 3(a) the characteristic peaks of the monoclinic structure at $703 \mathrm{~cm}^{-}$ ${ }^{1}$ and $805 \mathrm{~cm}^{-1}$ which are attributed to symmetric and antisymmetric (O-W-O) stretching mode in the ab plane, respectively $[26,27,28]$. The broad Gaussian shape of the $703 \mathrm{~cm}^{-1}$ band indicates a local disorder. The peak at $915 \mathrm{~cm}^{-1}$, usually observed in the range $920-970 \mathrm{~cm}^{-1}$ is attributed to terminal oxygen bonding [29] in case of nanocrystalline structures, or to the symmetric axial stretching of apical oxygen (along c-axis) [26], or to hydrated oxides $\left(\mathrm{WO}_{3} \mathrm{nH}_{2} \mathrm{O}\right)$ [27]. The attribution of the peak at $640 \mathrm{~cm}^{-1}$ is not clear, corresponding to an out-of-plane wagging mode $\gamma(\mathrm{O}-\mathrm{W}-\mathrm{O})$ [26], to a vibration of $\mathrm{WO}_{3} \cdot \mathrm{nH}_{2} \mathrm{O}$ $[27,29,30]$, or to a stretching of $\mathrm{W}_{3} \mathrm{O}_{9}$ hexagonal phase $\left(\mathrm{h}-\mathrm{WO}_{3}\right)$ [27]. The weak peak at $770 \mathrm{~cm}^{-1}$ is often observed on amorphous tungsten oxides [29] and described as a shoulder of the symmetric stretching mode. Finally the weak band at $847 \mathrm{~cm}^{-1}$ originates from the signal of peroxo groups (stretching W-O-O) [31]. The three main Raman bands clearly characterise our sample as a nanocrystalline $\mathrm{m}-\mathrm{WO}_{3}$ phase and according to their attributions the three weaker bands suggest the presence of defects (amorphous or hexagonal phases) and chemical impurities (hydrated and peroxo groups). 


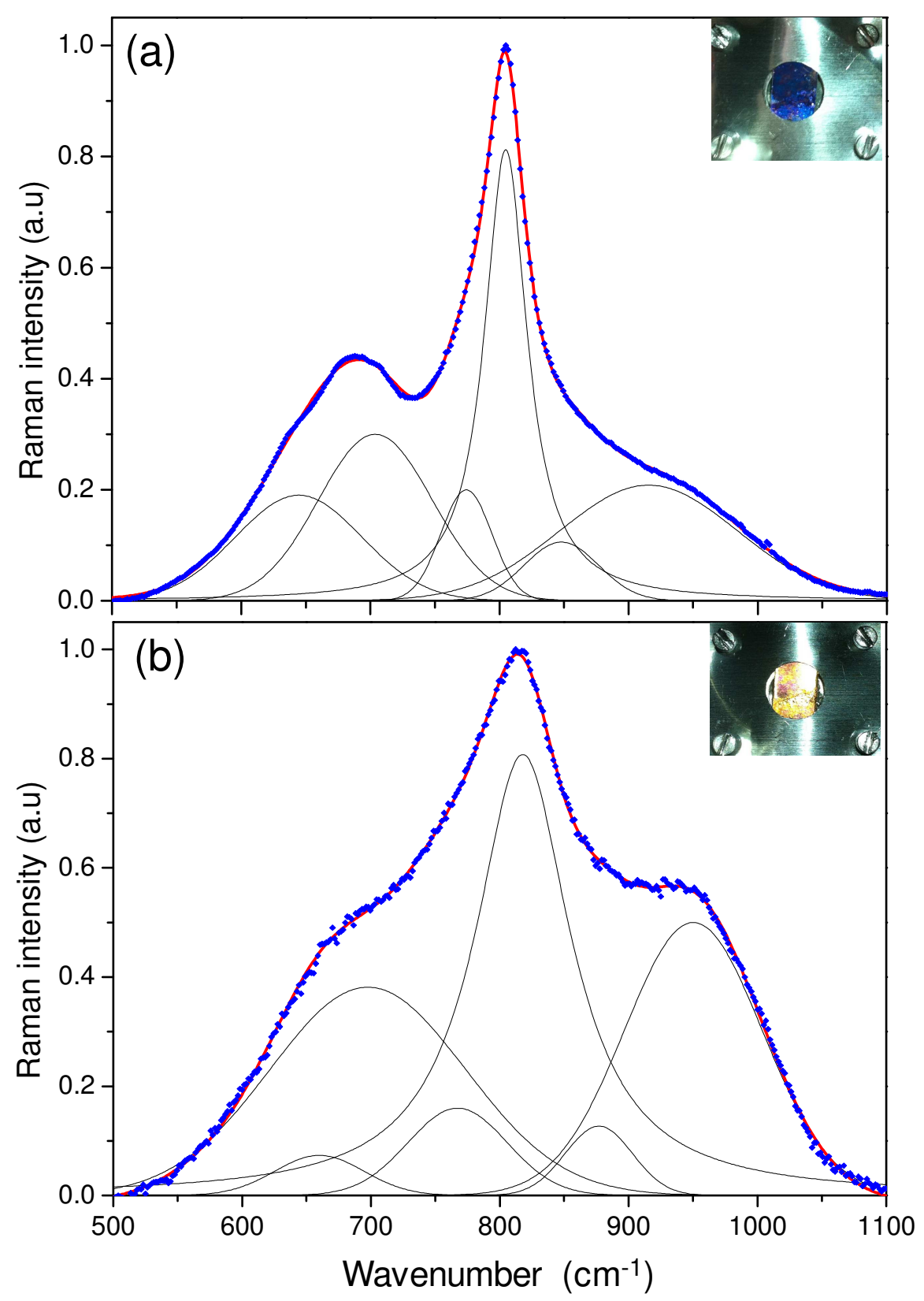

Fig. 3. Raman spectra of the $134 \mathrm{~nm} \mathrm{WO}_{3}$ layer $\left[\mathrm{T}=673 \mathrm{~K}, \mathrm{P}\left(\mathrm{O}_{2}\right)=590\right.$ Torr , $1 \mathrm{~h}$ ] (a) before (b) after exposure to deuterium plasma $\left(410^{17} \mathrm{D}^{+} / \mathrm{m}^{2}\right.$ with $\left.11 \mathrm{eV} / \mathrm{D}^{+}\right)$. ( $\left.\diamond\right)$ experimental data (-) fit

After exposure, we can note in Figure 3(b) that all the bands are broadened and shifted, with no more signature of the initial oxide spectrum, showing a modification of the whole $\mathrm{WO}_{3}$ layer and suggesting a deep diffusion of deuterium through the oxide layer as observed in [5]. There is also a significant increase of the bending vibration intensity $\left(100-500 \mathrm{~cm}^{-1}\right.$, not shown here) suggesting an increase of disorder. The peaks at 703 and $805 \mathrm{~cm}^{-1}$ are broadened and shifted to $697 \mathrm{~cm}^{-1}$ and $817 \mathrm{~cm}^{-1}$ (typical of $\mathrm{h}-\mathrm{WO}_{3}$ peak positions $\left.[22,27,32]\right)$ with no change in their relative intensity, which indicates a phase transition induced by the D implantation. A similar behaviour has previously been observed using XRD in studies on the electrochromic effect when a low voltage is applied to a $\mathrm{WO}_{3}$ layer [22]. The peak at 
$915 \mathrm{~cm}^{-1}$ has been shifted to $950 \mathrm{~cm}^{-1}$ with a noticeable increase of intensity showing the creation of oxygen terminal bonds. The three weak peaks at $640 \mathrm{~cm}^{-1}, 770 \mathrm{~cm}^{-1}$ and $840 \mathrm{~cm}^{-1}$ are slightly modified both in position and in width showing that they are sensitive to the modification of environment subsequent to D-bombardment. A few days after exposure, the Raman signature of the layer is getting closer to the spectra before exposure, together for the peak positions, the band widths and the band relative intensities. Only the intensity of the terminal bond modes $\left(\sim 920 \mathrm{~cm}^{-1}\right)$ remains large. Raman analysis then confirms the reversibility phenomena under ambient conditions suggested by the colour evolution of the sample and shows the formation of a more defective (local disorder, terminal bonds) monoclinic structure. Further experiments using He bombardment could help to differentiate chemical (reactivity with oxygen) and physical effects (structure defects) induced by D-bombardment. Bombarded samples could also be stored under vacuum in order to study the effect on reversibility.

\section{Conclusion}

Thin tungsten oxide layers with a nanocrystalline monoclinic structure have been formed under thermal oxidation growth at $\mathrm{T}=673 \mathrm{~K}$ and $\mathrm{P}\left(\mathrm{O}_{2}\right)=590$ Torr. The reflectance of these thin layers has been measured in the $2.5-16 \mu \mathrm{m}$ range: reflectance decreases as thickness increases, with a strong decrease at low wavelength which could impact IR diagnostics designed for ITER and WEST. Low energy deuterium bombardment results in a tungsten bronze $\left(\mathrm{D}_{\mathrm{x}} \mathrm{WO}_{3}\right)$ formation throughout the layer. There is a deuterium intercalation in the oxide channels which slightly modifies bond lengths and leads to a phase transition from monoclinic to hexagonal $\mathrm{WO}_{3}$ which has been clearly evidenced by Raman microscopy. It also induces an electrochromic effect which has been directly observed by a colour change. This behaviour is a consequent of the open structure of $\mathrm{WO}_{3}$ and of the deep diffusion of deuterium throughout the layer. A return toward the initial $\mathrm{WO}_{3}$ structure under ambient conditions is observed and possibly due to its oxidation. 


\section{Acknowledgements}

This work has been carried out thanks to the support of the A*MIDEX project ( ${ }^{\circ}$ ANR-11-IDEX-000102) funded by the "Investissements d'Avenir» French Government program, managed by the French National Research Agency (ANR)

\section{References}

[1] J. Roth et al., Data on low energy light ion sputtering, (1979)

[2] M.I Guseva et Al., J. Nucl. Mater 266-269 (1999)

[3] A. Pezzoli et Al., J. Nucl. Mater (2014) http://dx.doi.org/10.1016/j.jnucmat.2014.11.035

[4] N. Matsunami et Al, J. Nucl. Mater 390-391 (2009)

[5] V.Kh. Alimov et Al., J. Nucl. Mater 409 27-32 (2011)

[6] Gorbunova, K.M. et Al., J. Chem. Phys., Vol. 53,/149 No. 10, p. 871, 1956.

[7] Erik Lassner and Wolf-Dieter Schubert, Tungsten Properties (1999)

[8] P.R. Roberge, Handbook of Corrosion Engineering, Mc Graw Hill (2000)

[9] Gulbransen, E.A. et Al., Trans. AIME, Vol. 175, p. 611, 1948

[10] Cifuentes S.C et Al. Corrosion Science 114-21 (2012)

[11] V.Ye. Ivanov et Al., "Atom" Press (1968)

[12] E. A. Gulbransen et Al., Metals Technology, vol.14, pp. 611-627 (1947).

[13] P.M Woodward, A.W Sleight, T. Vogt, J. Solid State Chem. 131 9-17 (1997)

[14] M. Righettoni et Al., Materials research bulletin 59 199-204 (2014)

[15] R.D. Bringans et Al., Surface Sci. 111 (1981) 80

[16] R.D. Bringans et Al., Phys. Rev. B 24 (1981) 3481

[17] Ahmad A. et Al. Plasma Sources Sci. Technol. 22025006 (2013)

[18] M.C Rao et Al., Reaserch Journal of Chemical Sciences Vol. 1(7), 76-80 (2011)

[19] C. V. Ramana et Al., ACS Applied materials and interfaces 5, 4659-4666 (2013)

[20] T. Vogt et Al., Journal of Solid State Chemistry, 144,209-215 (1999)

[21] C. Wagner, Z. Phys. Chem. B21 25 (1933)

[22] Y. Djaoued et Al., Journal of Nanomaterials doi:10.1155/2012/674168 (2012)

[23] P.R Bueno et Al., Journal of applied physics 96 2102-2109 (2004)

[24] D. Chatzikyriakou et Al., Electrochimica Acta 137, 75-82 (2014)

[25] H. Zheng et Al., Advanced fonctionnal materials, 21 2175-2196 (2011)

[26] J. Santos Coelho et Al., J. Raman Spectrosc. 2009, 40, 1150-1157 (2009)

[27] M. F. Daniel et Al., Journal Of Solid State Chemistry, 67, 235-247 (1987)

[28] P. Tagtstrom, U. Jansson, Thin Solid Films 352 107-113 (1999)

[29] C. Santato et Al., J. Am. Chem. Soc, 123, 10639-10649 (2001)

[30] T. Kubo, Y.Nishikitani, J. Electrochem. Soc. 145(5) (1998) 1729 
[31] G. A. de Wijs et Al., Electrochimica Acta 46 (2001) 1989-1993 